\title{
BREVE REFLEXÃO SOBRE AUTOCUIDADO NO PLANEJAMENTO DE ALTA HOSPITALAR PÓS- TRANSPLANTE DE MEDULA ÓSSEA (TMO): RELATO DE CASO
}

Silva LMG. Breve reflexão sobre autocuidado no planejamento de alta hospitalar pós-transplante de medula óssea (TMO): relato de caso. Rev Latino-am Enfermagem 2001 julho; 9(4):75-82.

Este estudo teve por objetivo construir um instrumento que caracterizasse as demandas de autocuidado terapêutico de um indivíduo submetido ao TMO, refletindo sobre as intervenções de enfermagem no planejamento de alta hospitalar na óptica da teoria de autocuidado de Orem. Pelos critérios de inclusão obteve-se um indivíduo pós-TMO alogênico, portador de Leucemia Mielóide Crônica. A análise dos dados possibilitou avaliar os requisitos de autocuidado alterados e as intervenções de enfermagem se inseriram no sistema apoio-educação e no sistema parcialmente compensatório. 0 instrumento deverá ser refinado, mas pode-se sugerir sua utilização como suporte para a elaboração do planejamento de alta para pacientes de TMO.

PALAVRAS CHAVE: autocuidado, enfermagem, transplante de medula óssea

\section{A BRIEF REFLECTION ON SELF-CARE IN HOSPITAL DISCHARGE PLANNING AFTER A BONE MARROW TRANSPLANTATION (BMT): A CASE REPORT}

The purpose of this work was to construct an instrument that would enable the characterization of therapeutic self-care needs of an individual submitted to bone marrow transplantation (BMT) by reflecting on nursing interventions in the planning of hospital discharge based on Orem's self-care theory. The inclusion criteria consisted in the selection of allogenic clients who had been submitted to BMT and presented chronic myeloid leukemia. Data analysis enabled the evaluation of modified self-care requirements and nursing interventions were included in the support-education system and in the partly compensatory system. The instrument must be refined, but its use can be suggested as a support for the elaboration of the planning of hospital discharge for BMT patients.

KEY WORDS: self-care, nursing, bone marrow transplantation

\section{BREVE REFLEXIÓN SOBRE LO AUTOCUIDADO EN PLANEAMIENTO DE LA ALTA DESPUÉS DEL TRANSPLANTE DE MÉDULA ÓSEA: INFORME DE CASO}

Este estudio tuvo por objetivo construir un instrumento para caracterizar las demandas del autocuidado terapéutico de un individuo sometido al transplante de médula ósea, reflexionando acerca de las intervenciones de la enfermería en la planeación de la alta hospitalaria, desde la óptica de la teoría del autocuidado de Oren. Por los criterios de inclusión se obtuvo una persona sometida al transplante del médula ósea alogénico, Portador de Leucemia Mieloide Crónica. El análisis de los datos permitió la evaluación de los requisitos de autocuidado alterados y las intervenciones de enfermería se situaron en el sistema apoyo-educación y en el sistema parcialmente compensatorio. El instrumento deberá refinarse, pero se puede sugerir su utilización como apoyo para la elaboración de la planeación del alta hospitalaria, para los pacientes del transplante de médula ósea.

PALABRAS CLAVES: autocuidado, enfermería, transplante de médula ósea

\footnotetext{
${ }^{1}$ Enfermeira Mestre em Enfermagem pela Escola de Enfermagem da Universidade de São Paulo, Especialista em Oncologia. Enfermeira "Master" do Hospital Israelita Albert Einstein. Trabalho apresentado à disciplina Autocuidado na Assistência de Enfermagem, do Programa de Pós-Graduação Nível Mestrado da Escola de Enfermagem da Universidade de São Paulo, e-mail: giunta@zaz.com.br
} 


\section{INTRODUÇÃO}

OTransplante de Medula Óssea (TMO)é uma modalidade terapêutica que utiliza altas doses de quimioterapia e/ou radioterapia, seguido do resgate com medula óssea, com células progenitoras do sangue periférico (CPSP), ou com células obtidas do sangue de cordão umbilical. É denominado autólogo, quando se utiliza medula óssea ou CPSP do próprio paciente; singênico quando o doador é irmão gêmeo univitelino; alogênico quando o doador é irmão idêntico para o sistema antígeno leucocitário humano (HLA), quando o doador é irmão ou outro parente HLA haploidêntico ou parcialmente idêntico ou se o doador for não aparentado e HLA fenotipicamente idêntico ${ }^{(1)}$.

É indicado em patologias malignas ou não, modificando significativamente o prognóstico de pacientes portadores de doenças que, até alguns anos atrás, eram fatais. Entretanto, o TMO é um procedimento agressivo, de alto custo financeiro, acarretando severos efeitos colaterais, além de outras complicações e fatores de tensão físicos e psicológicos vivenciados pelo paciente e família ${ }^{(2)}$. Além disto, é necessário 0 acompanhamento ambulatorial por um longo período, após a alta hospitalar, durante o qual existe a possibilidade de uma série de complicações, decorrentes do tratamento ${ }^{(1,3-5)}$. Assim, por ocasião da alta hospitalar, o paciente deverá estar apto para assumir as ações necessárias para dar continuidade ao tratamento, lidar com suas conseqüências e retomar sua vida, o que implica em adquirir novos conhecimentos e habilidades, adaptar-se às condições impostas pela terapêutica, reunir os recursos necessários e engajarse no processo de recuperação, que podem ser caracterizadas como ações de autocuidado, segundo a teoria de Orem ${ }^{(6)}$. Por conseguinte, a enfermagem precisa aprofundar seus conhecimentos sobre estes pacientes do ponto de vista de suas necessidades, capacidades, limitações e dificuldades, de forma a auxiliá-los a atravessar esta experiência como elementos ativos do processo e não apenas como expectadores das ações dos profissionais de saúde.

Autocuidado $^{(6)}$ é o conjunto de ações que o ser humano desenvolve consciente e deliberadamente, em seu benefício, no sentido de promover e manter a vida, o bem estar e a saúde. Alguns requisitos necessários à ação de atutocuidado e de cuidado dependente são comuns a qualquer ser humano e outros se manifestam apenas quando ocorre a situação de doença ou dano à saúde, são eles: 1)Requisitos Universais - relativos à manutenção da vida, estrutura e funcionamento humano; 2) Requisitos no Desenvolvimento - são aqueles necessários às condições de mudanças ao longo dos diferentes estágios do ciclo de vida e que requerem adaptação, atuando no desenvolvimento e maturação do indivíduo, e 3) Requisitos de Desvio de Saúde - são necessidades de autocuidado que se apresentam nos casos de doença ou incapacidade e nos tratamentos exigidos para corrigir esta condição.

Capacidade de autocuidado significa a habilidade do indivíduo em executar ações que atendam suas necessidades. A capacidade de envolver-se e executar estas ações é aprendida e está sujeita a alguns fatores como idade, experiências de vida, valores, crenças, cultura em que se está inserido, recursos, gênero e educação, sendo denominados fatores condicionantes. A demanda de autocuidado terapêutico engloba todas as ações necessárias para manter a vida e promover a saúde e bem estar. Caso a demanda do autocuidado terapêutico exceda a capacidade de autocuidado do indivíduo temos a caracterização do déficit de autocuidado, onde se insere a atuação da enfermagem. Esta atuação, se dá em três diferentes sistemas, que são ${ }^{(6)}:$ 1) Sistema totalmente compensatório - quando a capacidade de autocuidado é limitada ou ausente e 0 enfermeiro responde por decisões e/ou ações necessárias à satisfação dos requisitos de autocuidado; 2) Sistema parcialmente compensatório - aqui paciente e enfermeiro realizam ações de autocuidado, alternando-se no papel de principal agente de autocuidado em função das limitações, conhecimentos e habilidades do paciente, e 3) Sistema apoio-educação - quando o paciente está apto e pode ou deve aprender a realizar as ações de autocuidado terapêutico, porém, não obtém êxito sem auxílio. Aqui o desempenho do enfermeiro está centrado em promover este paciente a um agente de autocuidado.

A teoria do autocuidado pressupõe que 0 indivíduo seja sujeito ativo no processo de decisão sobre a identificação das necessidades, da natureza e das ações a serem desenvolvidas no cuidado à saúde. Esta forma de abordagem enfatiza a participação do indivíduo e/ou familiares no processo de tomada de decisões, acerca do tratamento e dos cuidados necessários, de forma a possibilitar e incentivar a maior independência possível, deste indivíduo, na relação enfermeiro/paciente ${ }^{(7)}$, assim, o trabalho com o cliente é diferente do trabalho para ou pelo cliente... devendo, necessariamente, englobar a discussão de experiências e formas de se cuidar ${ }^{(8)}$. Neste enfoque o enfermeiro assume o compromisso de compartilhar conhecimentos, dividindo o espaço com aquele que é 0 sujeito e não mais o objeto das ações de cuidado à saúde.

Considerando-se a importância do engajamento do paciente de TMO na sua reabilitação, optou-se por desenvolver este trabalho que teve por objetivos: 1) Construir um instrumento a fim de avaliar os requisistos de autocuidado no planejamento de alta de um paciente submetido ao TMO; 2) Caracterizar a demanda de autocuidado terapêutico e identificar os sistemas nos quais estariam inseridas as intervenções de enfermagem.

\section{METODOLOGIA}

O estudo foi realizado a partir da solicitação da disciplina "Autocuidado na Assistência de Enfermagem", de que fosse elaborado 
um instrumento que avaliasse os requisistos de autocuidado de pacientes da área de interesse de cada aluno, como parte dos requisitos para integralização dos créditos do Programa de PósGraduação, nível Mestrado, da Escola de Enfermagem da Universidade de São Paulo (EEUSP). Foi construído um instrumento contendo questões abertas e fechadas, abrangendo questões referentes aos requisitos universais, de desenvolvimento e de desvio da saúde que poderiam estar alterados em função do TMO, bem como os fatores condicionantes importantes neste processo, que possibilitassem a determinação dos conhecimentos do paciente submetido ao TMO, sobre as ações de autocuidado a serem desenvolvidas no domicílio após a alta hospitalar. Após a elaboração, o instrumento foi apresentado ao professor responsável e aos alunos da disciplina Autocuidado na Assistência de Enfermagem, com a finalidade de se determinar sua coerência com o referencial teórico e com os dados que seriam importantes levantar. 0 instrumento foi aplicado em um paciente em fase de preparação para alta hospitalar pós-TMO, por meio de uma entrevista. 0 consentimento, em participar do estudo foi solicitado e obtido, do paciente e seu pai, após a exposição dos objetivos e o esclarecimento de que a participação seria de caráter voluntário. A entrevista foi realizada no dia nove do mês de junho de 1997 e a alta estava prevista para o dia catorze de junho de 1997; o instrumento foi aplicado pela enfermeira da unidade de TMO de um hospital filantrópico, de atendimento a pacientes com câncer, da cidade de São Paulo, que possui uma unidade de TMO. A análise foi realizada em duas etapas: em relação às demandas de autocuidado terapêutico identificadas e em relação aos aspectos referentes ao instrumento.

\section{RESULTADOS E DISCUSSÃO}

Demanda de autocuidado terapêutico

Este paciente é um adolescente de 15 anos, do sexo masculino, solteiro, estudante do segundo grau, católico não praticante, procedente e residente na cidade de São Paulo, com os pais e dois irmãos. Portador de Leucemia Mielóide Crônica (LMC) há seis meses, foi submetido ao TMO alogênico e estava com trinta e sete dias pós-transplante no momento da aplicação do instrumento. Sua residência é de alvenaria e conta com: telefone, rede de esgoto, água encanada, situando-se em rua asfaltada. Possui convênio/ seguro saúde e referiu não ter dificuldades em custear as despesas do tratamento. Após a alta hospitalar comparecerá aos retornos com o pai, que possui carro, tendo estimado o tempo de percurso em cerca de dez minutos, se não houver trânsito intenso. Em caso de urgência as condições de transporte seriam as mesmas e para acesso à equipe de TMO citou o número do telefone da unidade de transplante. Referiu que, atualmente, não apresenta cansaço aos esforços ou dificuldade em respirar profundamente.

A análise dos dados sugere que o paciente conhece as orientações gerais, mas não sabe detalhar as ações de autocuidado necessárias para dar continuidade ao tratamento em casa, após a alta hospitalar. Com relação ao tempo gasto no percurso entre a residência e o atendimento médico em situação de urgência, chama a atenção que paciente parece não atentar para 0 fato de que 0 trânsito pode atuar como fator de retardo no atendimento e dificultar seu acesso à equipe de TMO, o que pode se constituir num grave obstáculo caso não sejam discutidas alternativas para reduzir o tempo gasto no percurso em caso de tráfego intenso.

Com relação às orientações sobre alimentação suas respostas merecem discussão. A avaliação sobre ser suficiente a atual ingesta alimentar salienta o fato de não conseguir ingerir maiores quantidades de alimentos e não sentir fome nos intervalos. Suas expectativas pós-alta são sobre quais lanchonetes poderá freqüentar com os amigos, verbalizou vontade de tomar um sundae e comer churros - situações das quais está afastado há muito tempo e que não poderá retomar por enquanto. A inapetência embora compreensível, dadas as freqüentes complicações como: náuseas, vômitos, alterações do paladar, anorexia, etc. que acometem 0 paciente de TMO, é preocupante porque são comuns 0 emagrecimento e perda de massa corporal durante TMO. A manutenção de uma adequada ingesta de alimentos é fundamental não só como atendimento a um requisito universal de autocuidado como, também, para oferecer os substratos necessários ao processo de recuperação. Adicionalmente, existem restrições importantes no que se refere à prevenção de infecções, que podem ser adquiridas pela ingestão de alimentos preparados de forma inadequada, ou que não possam ser cozidos ou descascados possuindo, portanto, grande possibilidade de contaminação com bactérias e que levariam a um processo infeccioso grave ${ }^{(9)}$. A enfermagem em parceria com a nutricionista pode sugerir cardápios mais leves, em intervalos menores, compostos de alimentos que sejam da preferência do paciente (dentre aqueles permitidos pela sua condição), de forma a estimular sua ingesta e recuperar seu apetite. A investigação e discussão, com o paciente e seus pais, destas preferências, possibilidades de oferta, disponibilidade de preparo, cuidados higiênicos, riscos oferecidos por uma infecção gastrointestinal, etc. são determinantes para o prognóstico de curto prazo. Os dados sobre a ingesta hídrica sugerem manutenção adequada deste requisito, mas seria pertinente reforçar para este paciente a importância de manter-se hidratado uma vez que a ciclosporina, medicação utilizada para se obter a imunossupressão, necessária para evitar a rejeição do enxerto ou a doença do enxerto contra o hospedeiro (DECH), é nefrotóxica e freqüentemente determina comprometimento renal. 
O paciente afirmou que não havia em sua casa crianças em idade de tomar vacinas, entretanto, uma de suas expectativas ao retornar para casa é rever sua prima de 4-5 anos idade. É recomendável a discussão das possíveis complicações decorrentes de contaminações com agentes da varicela, gripes, etc., que poderiam estar sendo transmitidas pela criança (inadvertidamente), caso não sejam muito bem excluídas as possibilidades de contato prévio, desta sua prima, com outras crianças adoentadas - ainda que ela esteja sadia - e observados os períodos de incubação ${ }^{(9)}$.

0 afastamento de suas atividades rotineiras, como verbalizado na questão sobre atividades que desenvolvia: trabalha na locadora do pai... estuda a noite, associada às expectativas de reencontrar os amigos, freqüentar lanchonetes, deixar 0 ambiente hospitalar, etc., confrontam-se com o conhecimento relatado das limitações a que estará sujeito após a alta: evitar aglomerações,... evitar contato com pessoas com doenças infecciosas e com as atividades predominantemente solitárias verbalizadas quando indagado sobre o que pretende fazer durante 0 dia, após a alta: assistindo TV, filme, jogando vídeo-game. Isto pode sugerir uma dificuldade em aceitar as limitações impostas pelo tratamento, constituindo-se em uma alteração nos requisitos universais de equilibrio entre interação social e solidão. Além disto, a adolescência é um período evolutivo do ser humano, marcado pela busca da identidade e limitações nesta fase da vida tendem a comprometer os requisitos de desenvolvimento merecendo uma melhor investigação, que não foi possível nesta oportunidade, de forma a auxiliar o paciente neste período prevenindo sua não aderência ao tratamento e 0 prejuízo de seu desenvolvimento.

Com relação aos animais de estimação os dados colhidos referem-se a dois cachorros, um gato e oito hamsters. Estes animais são considerados, pelo paciente, como se fosse da família. Em seu relato esclarece que permanecem fora da casa e que existem pessoas que podem cuidar dos animais até sua recuperação. Entretanto, é pertinente retomar a discussão sobre os riscos, oferecidos por estes animais, a um indivíduo severamente imunossuprimido que incluem a toxoplasmose e infestação por parasitas ${ }^{(9)}$.

$\mathrm{Na}$ abordagem sobre mobilidade/locomoção informou que às vezes sente tontura. Esta informação merece maior investigação por favorecer quedas e ferimentos potencialmente graves. Embora os níveis de neutrófilos possibilitem a alta, os níveis de plaquetas e hemácias demoram um tempo maior para voltarem à normalidade $\mathrm{e}$ uma queda em um indivíduo trombocitopênico pode determinar sangramentos e ferimentos graves, ou mesmo fatais. 0 enfermeiro deve discutir esta questão com o paciente e/ou familiares, enfatizando a necessidade de evitar atividades extenuantes logo após a alta hospitalar, buscando o equilíbrio entre as atividades físicas que serão possíveis e seu posterior aumento gradual.
Sobre o cateter venoso central, o paciente afirma conhecer e dispor dos recursos necessários para realização do curativo, porém, não especifica de forma clara que recursos seriam estes (soluções anti-sépticas, gaze, fita adesiva, etc), limitando-se a informações vagas sobre fazer o curativo após o banho e lavagem das mãos. As dúvidas relatadas dizem respeito a uma das principais complicações do uso de cateter por tempo prolongado, em especial por pacientes imunossuprimidos, ou seja, infecção. Desconhece seus sinais/ sintomas, o que deve fazer em caso de urgência e quais atividades não poderá desenvolver enquanto fizer uso dele. Dado o grau de depressão imunológica e grave potencial de risco, no que se refere aos requisitos de desvio de saúde, é essencial que aprenda a reconhecer os sinais de infecção como: vermelhidão, dor, edema, crepitação ou presença de secreção no local de inserção e trajeto do cateter, que seja reforçada a impossibilidade de tomar banhos de piscina ou mar, pela facilidade de contaminação da via de acesso venoso, bem como a importância de mantê-lo limpo e clampeado, devendo ser heparinizado a intervalos determinados, a fim de se evitar a contaminação, hemorragias ou obstruções ${ }^{(9)}$. Todas estas informações devem ser discutidas e demonstradas, o curativo deve ser realizado pelas pessoas que serão responsáveis pelo cuidado em casa (segundo relato, ele próprio ou o pai), ainda no período de preparação para alta, dentro da unidade de $\mathrm{TMO}$, acompanhado pela enfermeira a fim de possibilitar a oportunidade de esclarecer dúvidas, minimizar a ansiedade e garantir o cuidado necessário.

Com relação à higiene pessoal, incluindo higiene oral, banho, cuidados com pele, unhas e cutículas, etc., suas respostas não possibilitam conhecer detalhadamente como deveria realizá-la. Frente esta situação recomenda-se retomar a discussão envolvendo o paciente, seus familiares e o enfermeiro, para que sejam esclarecidas as dúvidas de ambos os lados (o que o paciente realmente sabe, deseja saber ou sabe realizar). É importante esclarecer que embora já possa escovar os dentes, esta ação deve ser realizada cuidadosamente a fim de evitar traumas e lesões nas gengivas, que o uso do fio dental é desaconselhado até que obtenham contagens de plaquetas superiores a $50.00 / \mathrm{mm}^{3}$ e que as gengivas são susceptíveis de sangramento devido aos níveis de plaquetas e passíveis de hiperplasia devido ao uso de ciclosporina por tempo prolongado ${ }^{(9)}$.

$\mathrm{Na}$ abordagem sobre medicamentos que deverá continuar tomando após a alta hospitalar, suas respostas sugerem conhecimentos superficiais, nada sabendo sobre outras medicações além da ciclosporina. Esta medicação é de controle clínico delicado, devido aos seus efeitos colaterais e tóxicos. É importante salientar que os pais já haviam dado entrada ao processo para recebimento gratuito da droga, o que evidencia a busca dos meios para garantir a realização efetiva das medidas do tratamento. Porém, esta não é a 
única medicação a ser mantida após a alta, outras drogas visando a profilaxia de infecções (virais, fúngicas e bacterianas), da DECH, etc., serão receitadas a intervalos apropriados e de acordo com os efeitos tóxicos do tratamento sobre os demais órgãos ${ }^{(9)}$. Estas informações devem ser objeto de análise por parte do paciente, familiares e enfermeiro para que discutam sua importância na continuidade do tratamento, efeitos colaterais e sinais de toxicidade, garantindo a conscientização e regulagem dos efeitos danosos do tratamento.

Sobre as complicações decorrentes do TMO, que podem manifestar-se após a alta hospitalar, não foram identificadas dúvidas porque o paciente as desconhecia. Considerando o potencial de complicações pós-TMO, a larga faixa de tempo em que podem se manifestar - a imunossupressão celular e humoral demora de 6 meses (células B) a 2 anos (células T) para se recuperar completamente ${ }^{(4)}$, a freqüente irreversibilidade de algumas complicações - como a esterilidade e as dificuldades de caráter psicológico que os pacientes enfrentam ${ }^{(2,10)}$ é surpreendente que este paciente, faltando cinco dias para a data prevista para alta hospitalar, refira desconhecer tais complicações, caracterizando outro tópico que deve ser discutido pelo enfermeiro junto ao paciente e familiares.

Do ponto de vista da teoria do autocuidado ${ }^{(6)}$ a avaliação realizada, por meio do instrumento de coleta de dados, denota a inviabilidade do atendimento dos requisitos de autocuidado visto que essa teoria pressupõe a participação consciente e esclarecida do indivíduo nas ações de autocuidado. As possíveis complicações pósTMO, especialmente dos primeiros cem dias até um ano após 0 procedimento, devem ser discutidas entre paciente, familiares e enfermeiro para que seja viável o engajamento deste indivíduo em sua recuperação.

Sistema de enfermagem

A partir dos dados coletados e da análise realizada podese propor que as ações de enfermagem deveriam inserir-se, basicamente, no sistema apoio-educação e de forma complementar no sistema parcialmente compensatório. 0 sistema parcialmente compensatório terá o objetivo de executar ações para as quais 0 paciente e/ou familiar ainda não se encontram aptos. Neste estudo este sistema se aplica ao curativo do cateter, à administração de medicações, à identificação de sinais/sintomas de infecção e/ou urgências até que se encontrem aptos para realizá-las. 0 sistema apoio-educação adquire maior relevância, neste estudo, pelo fato do paciente se encontrar em fase de preparação para alta hospitalar, sendo necessário estimular sua participação e de seus familiares a fim de que estejam aptos a assumir seus papéis, pós-alta. As orientações e considerações feitas, durante a discussão dos resultados obtidos, são as que devem ser trabalhadas junto ao paciente e familiares.

A apresentação de um modelo da teoria de autocuidado adaptada ao atendimento de crianças e adolescente se faz necessária, uma vez que esta teoria focaliza particularmente 0 adulto. Quando o referencial teórico do autocuidado é aplicado em pediatria o papel dos pais ou da família é identificado como agente paterno, de forma que a demanda terapêutica de autocuidado pode ser atendida pela criança (agente de autocuidado), pelos pais (agentes paternos) ou pela enfermeira (agente de enfermagem). Nesta situação as decisões e as ações serão discutidas e decididas entre os três agentes e à medida que a capacidade da criança se desenvolve, no sentido de satisfazer as demandas de autocuidado, os papéis dos pais e da enfermagem diminuem. Com base nestas considerações deve haver um equilíbrio entre capacidade de autocuidado da criança e o agente paterno, que varia de acordo com a idade, habilidade, estágio de desenvolvimento, experiência de vida, crenças, e estado de saúde, estas variáveis que devem ser analisadas são os fatores condicionantes e crianças e adolescentes têm capacidade de desenvolver atitudes de autocuidado, porém, requerem auxílio e apoio da família, para que possam tornar-se independentes ${ }^{(7)}$. Assim, 0 adolescente pode ter sua capacidade de autocuidado desenvolvida, respeitados os seus limites e potenciais ${ }^{(6-7)}$. É importante que 0 enfermeiro promova este engajamento através da educação individualizada, evitando o "treinamento" de forma a estimular a motivação e evitando o desânimo, especialmente nesta etapa da vida onde as alterações físicas, psicológicas e emocionais são tão significativas. Alguns tratamentos, como o TMO, são longos, difíceis e exaustivos, entretanto, os pacientes devem ser estimulados a participar e decidir sobre as ações de autocuidado necessárias à sua recuperação. Estes estímulos devem ser oferecidos tanto pelos pais, quanto pelos profissionais envolvidos no processo. De outra forma a obrigatoriedade em seguir os princípios rígidos e limitantes do tratamento desencorajam estes pacientes e, com freqüência, dificultam a terapêutica.

Instrumento

As questões visavam obter o maior número de informações possível, sobre o conhecimento do paciente, em relação às ações de autocuidado que deveria executar em casa, após alta, bem como sobre seu cotidiano, a fim de verificar os pontos críticos que poderiam dificultar 0 desempenho destas ações e o seguimento ambulatorial pós-transplante, porém os resultados obtidos sugerem que alguns aspectos relevantes não puderam ser identificados por meio do instrumento, não apenas por não constarem do elenco de questões, mas também, porque algumas questões não foram exploradas satisfatoriamente. 
Inicialmente, no que tange às questões referentes aos fatores condicionantes, não constava do formulário indagação sobre o doador de medula óssea, caso o TMO fosse alogênico. Tal informação é importante uma vez que este tipo de TMO determina um pior prognóstico, de acordo com a compatibilidade do doador do ponto de vista do sistema HLA. Também não foi incluída uma questão sobre fase da doença, por ocasião do TMO, dado que pode ser coletados junto ao prontuário, sem sobrecarga para o paciente e que é igualmente importante para o prognóstico ${ }^{(1)}$. Nos dados referentes à alimentação, considerando que existem cuidados definidos e relatados em literatura ${ }^{(9)}$ sobre este assunto e que é importante que as informações sobre a dieta sejam as mais completas possíveis, teria sido aconselhável explorar quais foram as orientações fornecidas e 0 acréscimo de uma questão sobre quem forneceu as orientações poderia auxiliar a compreender melhor este item. As questões que continham os complementos como: "especifique o que você sabe ou as suas dúvidas", "por que?", etc. e que visavam detalhar o conhecimento e/ou opinião do paciente sobre os temas abordados, foram respondidas de forma geral não sendo possível determinar, em profundidade, quais eram os pontos críticos destes assuntos. 0 mesmo aconteceu com a questão sobre os cuidados de higiene pessoal, quando se indagou: "Você considera estes cuidados importantes?" Mediante resposta afirmativa, a justificativa limitou-se à frase risco de infecção, resposta vaga, não permitindo avaliar quais aspectos representam risco ou, ainda, diferenciar as variações deste risco em relação à realização ou não destes cuidados. Não havia uma questão que abordasse o tema afastamento do trabalho e/ou escola e as questões sobre expectativas e atividades que pretendia desenvolver, após a alta hospitalar, não foram suficientes para trazer 0 assunto à tona, de forma que não foi possível determinar se 0 afastamento do trabalho na locadora do pai ou das atividades escolares trouxe ou traria prejuízos para sua vida diária, tampouco quais as alternativas disponíveis para minimizar tais prejuízos, se houvessem.

O fato do instrumento não ter sido aplicado pela própria autora pode ter influenciado seu preenchimento uma vez que, embora

\section{Anexo}

\section{INSTRUMENTO PARA AVALIAÇÃO DOS REQUISITOS DE AUTOCUIDADO NO PLANEJAMENTO DA ALTA HOSPITALAR DE PACIENTES SUBMETIDOS AO TRANSPLANTE DE MEDULA ÓSSEA} (TMO)

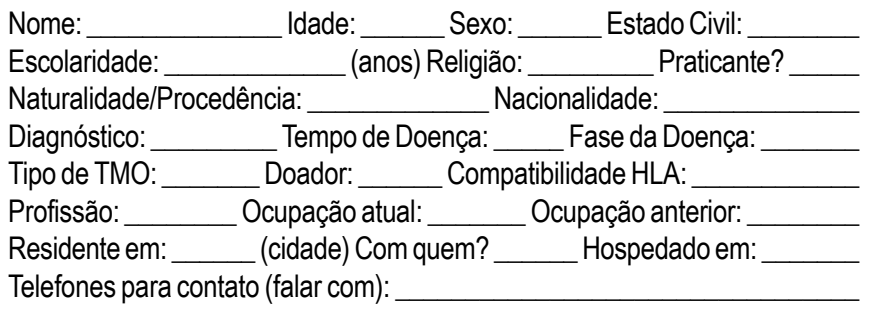

tenha havido a explanação de suas características e referencial teórico, não foi elaborado um roteiro para o preenchimento e, portanto, não havia como esclarecer as dúvidas do entrevistador durante a aplicação. 0 tempo gasto no preenchimento do formulário foi de 30 a 40 minutos sendo considerado extenso pelo paciente, entretanto a oportunidade em que foi aplicado parece ter influenciado este julgamento, uma vez que havia a expectativa de um procedimento invasivo (biópsia de medula óssea) a se realizar no mesmo dia. 0 período em que foi aplicado poderia ter sido melhor agendado, visto que faltavam cerca de cinco dias para a data prevista da alta hospitalar. Identificar os requisitos de autocuidado, mais precocemente, poderia permitir uma maior discussão da demanda de autocuidado terapêutico e da forma de atendê-la, proporcionando ao paciente e familiares a oportunidade de expressar suas dúvidas e ao enfermeiro a possibilidade de melhor capacitá-los para o enfrentamento desta nova etapa do tratamento.

\section{CONSIDERAÇÕES FINAIS}

De modo geral o instrumento permitiu a avaliação dos requisitos de autocuidado, apesar da limitação do tempo e de ter sido aplicado em apenas um paciente. Contudo, considerando esta aplicação como um pré-teste em que foi possível detectar a necessidade de alterá-lo, no sentido de refinar sua sensibilidade, é possível sugerir que seja considerado como suporte para o planejamento de alta sob a óptica da teoria de autocuidado de $\mathrm{Orem}^{(6)}$, auxiliando na implementação das intervenções de enfermagem. 0 papel do enfermeiro no transplante de medula óssea precisa ser mais discutido e divulgado, visto ser tão abrangente sua área de atuação. Os aspectos relativos aos pacientes devem ser mais bem estudados, tanto do ponto de vista clínico como psicossocial, visto que em relação aos estudos desenvolvidos em outros países, particularmente nos Estados Unidos e Canadá, podemos considerar que são poucos os trabalhos disponíveis, na literatura nacional, sobre a readaptação após a alta hospitalar de indivíduos submetidos ao TMO.

Utilizará condução para vir ao hospital? ( ) sim ( ) não Qual(is)? Tempo gasto no percurso: (estimado). Virá acompanhado? ( )sim ( ) não

Com quem? Em caso de urgência poderá estar no hospital em quando tempo? Como virá?

Há alternativas em caso de congestionamento? ( ) sim ( ) não Qual(is)? Tem conhecimento de como acessar a equipe de TMO? ( ) $\operatorname{sim}$ ( ) não. Como? A rua de sua casa é asfaltada? ( ) sim ( ) não. Sua casa tem água encanada? ( ) sim ( ) não. Sua casa tem rede de esgoto? ( ) $\operatorname{sim}$ ( ) não. Sua casa é de alvenaria? ( ) $\operatorname{sim}($ ) não

Você possui convênio/seguro saúde? ( ) sim ( ) não. Você tem alguma dificuldade em pagar as despesas do tratamento? ( ) sim ( ) não. Qual(is) Isto o preocupa? ( ) sim ( ) não. Por que? Como pensa em resolver este problema? 
Sente cansaço aos esforços? ( ) sim ( ) não. Em qual(is) situação(ões)? Tem dificuldade em respirar profundamente? ( ) $\operatorname{sim}$ ( ) não. Em qual(is) situação(ões)?

Você está preocupado com sua alimentação quando estiver em casa? ( ) $\operatorname{sim}$ ( ) não. Por que? Que informações você tem sobre a dieta que deverá seguir após a alta hospitalar?

Quem as forneceu? Quem preparará as suas refeições?

Esta pessoa foi orientada quanto aos cuidados que deve ter com sua alimentação? ( ) sim ( ) não. Quem orientou? dúvida? ( ) sim ( ) não. Qual(is)? Tem alguma dificuldade em manter os cuidados com sua alimentação? ( ) sim ( ) não. Qual(is)? se alimentar? ( ) sim ( ) não. Qual(is)

Quantas refeições consegue fazer por dia? suficiente? ( ) sim ( ) não. Por que? com seu peso atual? ( ) sim ( ) não. Por que?

Quanto bebe de líquidos (sucos, chá, leite, refrigerante, água, etc) durante 0 dia? Considera suficiente a quantidade de líquidos que ingere? ( ) sim ( ) não. Tem alguma dificuldade em beber líquidos? Qual(is)?

Quantas horas costuma dormir? Tem sono tranqüilo? ( )sim

( ) não

Quantas pessoas dormem no seu quarto?

O que facilita o seu sono? O que dificulta o seu sono? Costuma acordar à noite? ( ) sim ( ) não. Com

que freqüência? Porque?

Necessita de remédio para dormir? ( ) sim ( ) não. Costuma dormir durante o dia? ( ) sim ( ) não. Freqüência: Que atividades

desenvolvia durante o dia?

Quantas vezes evacua por dia? ____ Consistência: ( ) pastosa ( ) diarreica ( ) endurecida. Tem alguma dificuldade para evacuar? ( ) sim ( ) não.

Qual(is)? Quantas vezes urina por dia?

Tem alguma dificuldade para urinar? ( ) sim ( ) não. Qual(is)?

Possui banheiro privativo? ( ) sim ( ) não

Em sua casa existem crianças em idade de tomar vacinas? ( ) sim ( ) não. Quantas pessoas moram na sua casa? Você terá companhia em casa nas 24 horas? ( ) sim ( ) não. Por que?

Caso não tenha companhia nas 24 horas responda: somente no período da manhã ( ), somente no período da tarde ( ), somente a noite ( ), durante toda a noite? ( ) sim ( ) não. Quem Ihe fará companhia?

Que atividades pretende desenvolver quando receber alta?

Você tem animais de estimação em casa? ( ) sim ( ) não. Caso tenha responda: Qual? Quanto ele é importante para você? Há alguém que possa tomar conta dele até você se recuperar? ( ) sim ( ) não. Você sabe quais os recursos necessários para realização do curativo do cateter? ( ) sim ( ) não. Especifique o que você sabe e/ou as suas dúvidas: Você tem acesso a estes recursos? ( ) sim ( ) não. Caso não tenha, como pensa em resolver 0 problema? Em casa, quem fará o curativo do cateter?_ Esta pessoa já foi orientada sobre os cuidados com

\section{REFERÊNCIAS BIBLIOGRÁFICAS}

1. Ferreira E. Transplante de medula óssea. In: Murad AM, Katz A. Oncologia, bases do tratamento. Rio de Janeiro (RJ): Guanabara Koogan; 1996. p. 96-106.

2. Andrykowski MA. Psychosocial factors in bone marrow transplantation: a review and recomendations for research. Bone Marrow Transplant 1994 April;13 (4):357-75.

3. Riul S. Contribuição à organização de serviços de transplante de medula óssea e à atuação do enfermeiro. [dissertação]. Ribeirão Preto (SP): Escola de Enfermagem de Ribeirão Preto/USP; 1995. o cateter? ( ) sim ( ) não. Você sabe identificar os sinais/sintomas de infecção no local do cateter? ( ) sim ( ) não. Você sabe o que deve fazer em caso de urgência relacionada ao cateter? ( ) sim ( ) não. Especifique o que você sabe ou as suas dúvidas: __ Você sabe o que deve fazer em caso de urgência relacionada ao cateter? ( ) sim ( ) não. Especifique 0 que você sabe ou as suas dúvidas: Você sabe quais atividades não poderá desenvolver enquanto estiver com o cateter? ( ) sim ( ) não. Especifique estas atividades__ Você sabe por que é necessário manter o cateter após a alta hospitalar? ( ) sim ( ) não. O que você pensa de ir para casa com o cateter?

Você tem dificuldade em se movimentar? ( ) sim ( ) não. Por que? Tem dificuldade para tomar banho? ( ) sim

( ) não. Por que? Precisa de auxílio para tomar banho? ( ) sim ( ) não. Tem dificuldade para vestir-se ou calçar-se? ( ) $\operatorname{sim}$ ( ) não. Por que? vestir-se ou calçar-se? ( ) sim ( ) não. Por que? Precisa de auxílio para dificuldade para escovar os dentes? ( ) sim ( ) não. Por que?

Você sabe quais os cuidados de higiene pessoal que deverá manter, em casa, após a alta hospitalar? ( ) sim ( ) não. Especifique o que você sabe: Você considera estes cuidados importantes?

( ) $\operatorname{sim}$ ( ) não. Por que?

Você tem dúvidas sobre os medicamentos que deverá continuar tomando após a alta hospitalar? ( ) sim ( ) não. Caso tenha sua dúvida é sobre (assinale e comente): Tipo de medicamentos? ___ Para que servem? Horário em que devem ser tomados?

Como tomá-los? Onde comprá-los?

Por quanto tempo irá tomá-los?

colaterais? Sinais de toxicidade?

Você sabe quais as complicações decorrentes do TMO que podem se manifestar após a alta hospitalar? ( ) sim ( ) não. Quais?

Você tem dúvidas sobre estas complicações? ( ) sim ( ) não. Caso tenha sua dúvida é sobre: Tipo de complicação? __________ Sinais e sintomas? Quando se manifestam? 0 que deve ser considerado urgência?

Você sabe que deve retornar às consultas agendadas? ( ) sim ( ) não. Caso saiba responda: Por que? Você sabe quais as limitações a que estará sujeito após a alta hospitalar? ( ) sim ( ) não. Especifique: O que você pensa sobre isto:

Está afastado do trabalho ou escola? ( ) sim ( ) não. Se estiver, como se sente sobre isso?

Qual(is) sua(s) expectativa(s) ao voltar para casa após a alta hospitalar?

Você tem alguma dúvida, em particular, que gostaria de discutir? ( ) sim ( ) não. Qual(is)?

Impressões do Entrevistador (estado emocional, interesse, etc):

Data da entrevista:_____Hora:__Data prevista para alta hospitalar:___ _ Ass. da Enfermeira e Registro no COREN 4. Wujcik D, Ballard B, Camp-sorrel D. Selected complications of allogeneic bone marrow transplantation. Semin Oncol Nurs 1994 February; 10 (1):28-41.

5. Garcia I, Wax P, Chwartzmann F. Aspectos psicossociais do paciente com câncer. In: Murad AM, Katz A. Oncologia, bases do tratamento. Rio de Janeiro (RJ): Guanabara Koogan; 1996. p. 12531.

6. Orem D. Nursing concepts of pratice. $5^{\text {th }}$ ed. St. Louis: Mosby-Year Book; 1995. 
7. Oliveira AG. Aplicação da teoria do autocuidado de Orem em adolescentes em diálise peritoneal ambulatorial contínua. Rev Gaúch Enfermagem; 1995;16 (12): 46-51.

8. Noronha R. Experiência participativa mobilizadora de enfermagem - condições prévias para o autocuidado. Rev Bras Enfermagem; 1986; 39 (1): 34-43.
9. Ford RN, Kenny S, Slevin R, editors. Bone marrow transplantation teaching plan. New York (NYC): Division of Nursing, Memorial SloanKettering Cancer Center; 1990.

10. Epelman CL. Quimioterapia em altas doses e transplante de medula óssea: aspectos psicológicos. Acta Oncol Bras 1997; 17 (2):67-9. 